\title{
Evaluation of the crystallization process of Stevia rebaudiana Bertoni
}

\author{
Giulia S. Matheus*, Carolina S. F. Picone.
}

\begin{abstract}
The present project propose to understand the mechanisms of stevia crystallization and to identify the factors that influence such crystallization. Three comercial samples with different concentrations of rebaudioside A were evaluated. Each sample was analized regarding their centesimal composition. Tests of absorbance, $\mathrm{pH}, \mathrm{XRD}$, optical microscopy and solubility were also carried out in different temperatures. The results showed that more concentrated solutions and elevated temperatures provide faster and more intense crystallization. Moreover, samples with a higher percentage of rebaudioside A (97\% and 95\%) have greater tendency to crystallize than those with low content of rebaudioside A $(60 \%)$, which did not crystallize in any of the situations studied.
\end{abstract}

\section{Key words:}

Crystallization kinetic, rebaudioside, sweetener.

\section{Introduction}

Nowadays, the search for foods with reduced sugars, fats and calories has grown intensely. Many studies in the area have gained space, among them the substitution of sucrose in food for another natural sweetener that presents similar characteristics to those of sucrose. Stevia, extract of leaves of Stevia rebaudiana Bertoni plant, is a sweetener with potential to serve this growing segment of natural foods. It presents high sweetening power and due to its composition (glycosides that are not metabolized by the body), low caloric value. Stevia also presents good chemical stability. However, it has a lower solubility than sucrose and a bitter residual taste, which could limit stevia industrial application.

Despite of its technological relevance, few information is available about stevia crystallization and the factors that influence such process still unknown. Thus, the aim of this project was to understand the mechanisms of stevia crystallization and identify how temperature, concentration and time influence such process.

\section{Results and Discussion}

Three commercial samples of stevia with different concentrations of rebaudioside A were studied $197 \%$ RA97, 95\% - RA95 and 60\% - RA60). In order to analyze the influence of solution concentration on the crystallization kinetics of samples, stevia solutions with two different proportions of sweetener and water (2:8 and 3:7) were prepared at room temperature $\left(25^{\circ} \mathrm{C}\right)$. The samples were analyzed by optical microscopy and spectrophotometry during time until stability. Different times were obtained for stabilization. For RA97 this time was about 120 minutes. For RA95 stabilization occurred in 240 minutes for the most concentrated solution and in 360 minutes for the least concentrated solution. After that, solubility tests were carried out. To evaluate the effect of temperature on stevia crystallization, the samples were also storage at $7^{\circ} \mathrm{C}$ and $43^{\circ} \mathrm{C}$ during 6 hours, than they were evaluated regarding their absorbance, morphology and solubility.
The results showed that the higher the percentage of rebaudioside $A$ in the commercial sample, more intense is the crystallization process. In addition, there was an intense crystals formation on more concentrated solutions. The process of crystallization was intensified and accelerated at higher temperature $\left(43^{\circ} \mathrm{C}\right)$. On the other hand, at $7^{\circ} \mathrm{C}$ the formation of the crystals was drastically retarded. The crystals formed (Image 1) presented long rod shape, being classified as amorphous solids, since they did not present bi-refringence under polarized light. On solubility analysis, the samples maintained at $43^{\circ} \mathrm{C}$ presented considerably lower solubility than those kept at $7^{\circ} \mathrm{C}$ (a small solubility percentage corresponds to an intense crystallization process). The sample RA60 did not crystallized in any of the conditions studied, which is explained by it centesimal composition. RA60 was the sample with major percentage of impurities.

Image 1. Microscopy of sample RA97 in 2:8 ratio after 6 hours of preparation. A) $7^{\circ} \mathrm{C}$. B) $25^{\circ} \mathrm{C}$. C) $43^{\circ} \mathrm{C}$.

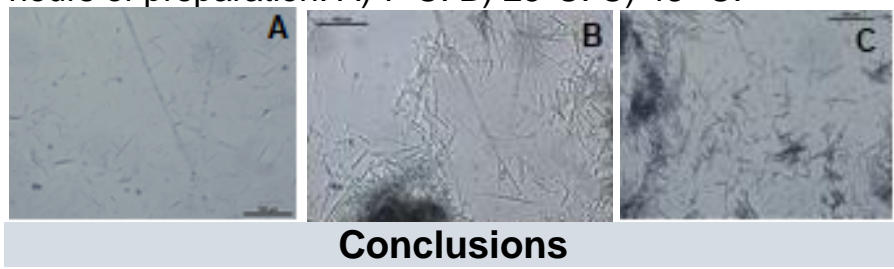

It was possible to conclude that the stevia crystallization process is influenced both by the rebaudioside A content, as well as by the concentration of the solutions prepared and the temperature at which such solutions are storage. Thus, the results obtained will help to increase the possibilities of application of this sweetener in foods whose production and storage involves variations of concentration and temperature.

Acknowledgement

The authors thank PIBIC/CNPq and CAPES for the financial support, FEA-Unicamp and FEQ-Unicamp for the colaboration and prof. Mariana Conceição da Costa and Rafael Macedo from LEF for help with the analysis of optical microscopy. 